J Cancer Educ. 2014 September ; 29(3): 570-576. doi:10.1007/s13187-014-0638-6.

\title{
Native Hawaiian Views on Biobanking
}

Maile Tauali'i, PhD, MPH ${ }^{1}$, Elise Leimomi Davis, MPH ${ }^{1}$, Kathryn L. Braun, DrPH ${ }^{1,2}$, JoAnn Umilani Tsark, MPH${ }^{2}$, Ngiare Brown, MD, BMED, MPHTM, FRACGP ${ }^{3}$, Maui Hudson ${ }^{4}$, and Wylie Burke, MD, PhD 5

${ }^{1}$ University of Hawai'i

2'Imi Hale, Papa Ola Lokahi

${ }^{3}$ National Aboriginal Community Controlled Health Organisation

${ }^{4}$ Te Kotahi Research Institute, University of Waikato

5 University of Washington

\section{Abstract}

Genomic science represents a new frontier for health research and will provide important tools for personalizing health care. Biospecimen-based research is an important mechanism for expanding the genomic research capacity, and indigenous peoples are a target of biospecimen-based research due to their relative isolation and the potential to discover rare or unique genotypes. This study explored Native Hawaiian perceptions of and expectations for biobanking. Ten discussion groups were conducted with Native Hawaiians ( $\mathrm{N}=92$ ), who first heard a presentation on biobanking. Six themes emerged: 1) biobank governance by the Native Hawaiian community, 2) research transparency, 3) priority of Native Hawaiian health concerns, 4) leadership by Native Hawaiian scientists accountable to community, 5) re-consenting each time specimen is used, and 6) education of Native Hawaiian communities. Considered together, these findings suggest that biobanking should be guided by six principles that comprise "G.R.E.A.T. Research:" (Governance, Re-consent, Education, Accountability, Transparency, Research priorities). These recommendations are being shared with biobanking facilities in Hawai' $i$ as they develop protocols for biobanking participation, governance, and education. These findings also inform researchers and indigenous peoples throughout the world who are working on biobanking and genomic research initiatives in their nations.

\section{Keywords}

biobanking; research; ethics; Native; Hawaiian; genomics; guidelines; disparities; cancer; indigenous

For correspondence about this manuscript, contact Kathryn Braun kbraun@ hawaii.edu, 808-330-1759 For reprints, contact Maile Tauali ‘i, 1960 East-West Road, Honolulu, HI 96822, Phone (808) 956-7231, Fax (808)956-5818, mtaualii@ hawaii.edu.

Conflict of Interest Disclosures: All authors have no financial disclosures. 


\section{Introduction}

Genomic science represents a new frontier for health research and will provide important tools for personalizing health care [1]. Biorepositories are facilities that collect and store specimens--for example blood, cord blood, placentas, and cancer tissue--for future research. Governments and commercial interests are supporting expansion of these resources to increase genomic research capacity. These efforts are not without controversy, especially among indigenous peoples. As small, relatively isolated populations, they have greater genetic homogeneity than more commonly studied populations and may have rare and uniquely informative gene variants. These qualities, combined with disproportional rates of disease, have made indigenous peoples the target of many genetic research studies and biobanking efforts [2-3]. Historical and contemporary violations of standards for research with human participants on the part of the research community have resulted in avid debates around research ethics involving indigenous peoples [1-6].

Globally, genetic research touches the lives of many indigenous peoples. However, responses to these efforts have differed by community. In Native Hawaiian communities, efforts to patent and genetically modify taro, the staple food of indigenous Hawaiians that figures predominantly in this people's creation, led to a legislated moratorium on this research [6-7]. An effort to map the Native Hawaiian genome was met with protests from the community and a call for education in genetics and ethical issues surrounding genetic studies that impact Native Hawaiians [8]. These events underscore the importance of incorporating indigenous peoples' perceptions and expectations of culturally appropriate and ethical research behavior as biobanking protocols, including informed consent procedures and related educational programs, are developed. While recent studies provide valuable insight into the perspectives on biobanking of other indigenous populations (e.g., Hiratsuka's work with Alaska Natives), few focus on the perspectives of Native Hawaiians, the indigenous peoples of the Hawaiian archipelago [9]. Native Hawaiians comprise about $23 \%$ of the population of Hawai'i, which also includes Whites (20\%), Japanese (20\%), Filipinos (18\%), Chinese (4\%), Koreans (2.5\%), Samoans (2.5\%), and others [10].

'Imi Hale Native Hawaiian Cancer Network ('Imi Hale, one of 23 Community Network Program Centers funded by the National Cancer Institute) has utilized Community Based Participatory Research (CBPR) principles to engage Native Hawaiians in discussions around biobanking. In a 2001 needs assessment involving 980 Native Hawaiians, genetic and biological research was identified as one of five priority issues for awareness and research [11]. However, participants were opposed to research that promotes outsider advancement, provides little or no benefit to participating communities, or uses results to stigmatize Native Hawaiians [12]. A 2004 survey of 357 Native Hawaiians assessed preferences for informed consent and disclosure of results from genetics research and compared findings against those from a White sample [13]. Native Hawaiians were more likely than non-Hawaiians to want to be consented for genetic research on stored samples (55\% vs. 33\%), and most would want results reported to them (87.6\%) and to their physician (79.0\%). However, no study has gathered in-depth qualitative data from Native Hawaiians on their knowledge, attitudes, and perceptions related to the collection of biospecimens. This study addressed this knowledge gap. 


\section{Methods}

Ten focus groups were conducted in English throughout the state of Hawai ' $i$, and analyzed using grounded theory methodology. [14] A Native Hawaiian researcher trained in facilitation led each focus group with the support of Native Hawaiian staff. All participants were consented and completed a short demographic questionnaire. Meetings were audio recorded, and notes and recordings were transcribed and analyzed. The study was approved by the Institutional Review Board of the Native Hawaiian Health Care Systems.

The 92 participants were recruited through convenience sampling with the help of Native Hawaiian-serving organizations, including the Native Hawaiian Health Care Systems (federally designated entities on all inhabited islands to improve the health and wellbeing of Native Hawaiians) and other Hawaiian-oriented groups. Participants were recruited by agency staff and through fliers that described the requirements for participation: 18 years or older, of Native Hawaiian ancestry, and English-speaking. Only those who met the inclusion criteria were approached by recruiters to participate in focus groups. Staff members from recruiting agencies were allowed to participate if they met the inclusion criteria and were interested. In addition to signing consent forms, participants completed a demographic questionnaire asking gender, age, education, employment, insurance status, and if they had previously heard about biobanking. No specimens were collected.

Focus group questions were developed based on a review of the literature, cognitive testing, and consultation with ten community advisors and six experts in the field. The core questions were further modified after the first focus group to improve the flow of discussion. The final questions were: 1) What do you think are some possible benefits of contributing your tissue or blood to a biobank for research? 2) What are some of your concerns about doing this? 3) How and when would you like to be asked to contribute your blood or tissue to a biobank? 4) What kinds of information, if any, would you want about the research study in which your blood or tissue is used? and 5) What would you think if several different researchers wanted to use you blood or tissue for several different kinds of research? The facilitator did not participate in the discussion, but served to help all participants voice their thoughts and opinions by clarifying focus group question if asked. All ten focus groups were held in community settings or agencies. Five groups were held on $\mathrm{O}^{\prime}$ ahu, two on Hawai ' $\mathrm{i}$ island, and one each on Kaua'i, Maui, and Moloka 'i. Each focus group lasted 90 to 150 minutes, and participants were provided refreshments and a $\$ 20$ gift card.

Because biobanking and specimen-related research are relatively new concepts, a 20-minute presentation developed by the lead author was provided prior to administering the focus group questions. Information in the presentation included a definition of biobanking, the reason biobanks are being created (i.e., to establish repositories of specimens that can be used in research to discovery causes of and cures for disease), that biobank findings probably would not benefit the specimen donor, and that researchers examining samples would not know the donor's name, but would likely know ethnicity, age, gender, and disease. Ethical issues specific to biobanking and indigenous peoples were outlined, and examples of how other indigenous peoples have addressed biobanking were shared. The concept of informed consent was reviewed, including the: 1) differences between passive 
and active consent; 2) options in the consenting process (i.e., donor giving blanket approval for the use of specimens in any research or donor opting to decide which studies their specimen could be used in); 3) options to not have one's specimen banked; and 4) options to withdraw one's specimen even after agreeing to banking.

Focus group transcripts were analyzed using NVivo 10 [14-15]. Data analysis began after the first focus group and continued throughout. Emerging ideas about the theoretical constructs and their relationships were memoed, and emerging insights caused us to listen in new ways at subsequent groups. We conducted ten focus groups to include all islands, although theoretical saturation was achieved after the eighth group. In reaching agreement on the final themes, we identified key words or phrases that were repeated across the transcripts. Transcripts were systematically searched to find all instances of the word or phrase (we called these codes). These code words and phrases and the immediate context were highlighted. We then physically sorted codes and their context into meaningful groups and assigned a logical thematic name to the cluster of codes. Finally, illustrative quotes were identified for each theme [14].

\section{Findings}

Of the 92 participating Native Hawaiians, most were female (78.3\%), 56.6\% were 50 years of age or older, and $33.7 \%$ had completed a bachelors degree or higher. One third (33.7\%) had heard of biobanking prior to the focus group.

In response to the first question about potential benefits of donating tissue to a biobank, participants across all groups expressed interest in and desire to participate in research. Across the ten focus groups, there were multiple references to the benefits of medical research and how it led to advancements in preventing, diagnosing, and treating disease. In all groups, at least one individual noted that participating in research operationalized the Native Hawaiian value of helping others and contributing to the common good. For example, one participant stated:

I mean honestly, we are a people of aloha, and we believe in the process of life. So yeah, I think it's in our individual's immediate action. For the most part our Hawaiian people want to help others, not just our own families, but we want to see people do well, regardless. And I hear that over and over again, it is part of our nature... it's part of that process that is in our natural reaction to care for others.

Responses to the other five questions led to thoughtful and fervent discussions about biobanking. From the analysis of these discussions, six themes emerged regarding Native Hawaiian expectations for banking biological specimens and their use in future research. First, respondents wanted Native Hawaiians to play a role in the governance of Hawai ' $\mathrm{i}$ based biobanks. Second, they wanted transparency in all aspects of research. Third, they felt biospecimen-related research should focus of Native Hawaiian health concerns. Fourth, they wanted more research to be led by Native Hawaiian scientists who were accountable to the Hawaiian community. Fifth, they felt that donors should have the option to be re-consented each time use of their specimen was requested. Sixth, they called for education of Native 
Hawaiian communities to increase understanding of tissue banking and tissue-related research. Each of these themes is discussed in more detail below.

\section{Governance by the Native Hawaiian Community}

At least one person in each focus group suggested that Native Hawaiians needed to play a large role in the governance of Hawai'i-based biobanks. Preference was for a biobank dedicated to the collection of Native Hawaiian specimens that was developed, managed, and governed by a Native Hawaiian organization. No specific organization was identified and some discussion included the need to develop a new organization to serve in this role. "If it was someone who had a cultural code, some kind of cultural code, if there was a cultural based organization, with a cultural code in place... But what I am suggesting is that there has to be some control over it (biobank) and feedback into the community."

\section{Research Transparency}

Participants noted multiple times that research is not widely understood by the general public and that, because of past human subject violations, some Native Hawaiians are mistrusting of research. As one participant stated:

I think it's really important what she's saying, the idea of being informed. You have informed choice here, but I never knew that when they took off my breast and they took out my 23 lymph nodes that they had a specimen. Nobody told me that, so being informed, like, gives us a wider perspective on how to deal with all this kind of stuff. I thinks it's really good because I believe we've been studied since we was babies as Hawaiians, but they take all the information and go away and don't come back to tell us - what, what happened from it. So this idea of being informed, of knowing the results -- I have been in so many pilot programs that I could fly an airplane, but I don't know what direction I'm going in. That's the thing. It's finally coming to light.

Another participant noted:

The first time I heard of biobanking was in the first year of law school. This guy who was suing, I don't know who, the hospital or what, he had a special blood type or tissue type and they ended making a multibillion dollar drug off of it. And he wanted a piece of that. And what we found out was that, no, he gave up that tissue basically the property rights were traded over to the biobank... When you give your tissue, the property rights that you have are extinguished. You have no control, which is the anxiety that a lot of us have. We literally have no legal control, which is what happened with the Havasupai tribe.

Despite having reservations about research, participants reiterated that most Native Hawaiians want to help others and that participation in research provides an avenue to do so. However, participants described wanting to be informed of all aspect of research. They discussed the desire for researchers to take the time to completely describe the project and ensure that participants are fully aware of what they are agreeing to.

Because we were raised with the attitude "no (don't) question," we come with that value. But now we beginning to know it is okay to ask the questions, "How come? 
How? Why? Where are we going with this?" This knowledge that we are gaining is so important for all of us and those that are still coming down the line. If I can help malama [care for] those that are still in the back of the canoe, still coming on the journey, on living life, a better life, I'm all for it. But I need to be informed and understand it. I want to know so that my children and my children's children will know.

Another participant talked about the difficulties of getting individuals to understand informed consent for future, unspecified research. Most informed consent documents refer to a specific, time-limited study, and the procedures to be performed on or with participants are clearly delineated. "But what kind of legal protections do we have then if there is no research question or purpose put forward. That's the confusing idea, and I think that's where a lot of anxiety is going to come from." As reflected in the comments about governance, a participant noted: "There should be a check and balance somehow, and to report back to the people that are part of this gathering and to always have notices out there, somehow, and where it's accessible."

\section{Research that Prioritizes Native Hawaiian Health Concerns}

Participants understood that, for the most part, researchers were trying to better understand diseases and advance treatments and cures. However, $70 \%$ of participants mentioned that they wanted biobanks in Hawai 'i to prioritize research to diseases experienced disproportionately by Native Hawaiians. Participants particularly mentioned cancer, heart disease, and diabetes as areas of focus for biospecimen-related research. "I would want to know who is using it? What is the benefit? What disease? Ideally I would want Hawaiians to benefit first. If there is a limited quantity of tissue in the biobank and disease is high for Native Hawaiians, I would want my tissue to be used for research that will help Native Hawaiians."

Some participants mentioned the traditional Native Hawaiian belief that one's mana (spirit or power) resides in all body parts. In traditional society, placentas were buried under a bush or tree, finger nail and hair clippings were hidden, and bones of the deceased were interred in secret places so that they could not be used by evil-doers to cast spells or otherwise harm the individual or family [16]. This belief may not be a barrier to biobank participation, but it underscores the need to treat donations and the consenting process with respect, reflecting appreciation for the fact that, in some cultures, the donation may be interpreted as a subjugation of one value (personal mana) by another value (collective good).

As a Native Hawaiian, I have to keep everything of me. That's my mana. I don't want it out there unless I choose to put it out there. So for Native Hawaiians like me who have this attitude, and doing the type of work we do, I know what's at stake, I know research is good, and we need more research specific to help our people. So I have to find that balance to be able to say, "Yeah use it." But, don't just take my tissue and use it for diabetes; take my tissue and use it for diabetes to help the Native Hawaiians. That I can agree to...because we don't have enough studies on us, the Native Hawaiians, so that we can get medicines that complement us. 


\section{Native Hawaiian Leadership in Research}

There were strong opinions about the need for Native Hawaiian researchers and health care practitioners. Participants felt Native Hawaiian researchers would be more sensitive to cultural values than non-Hawaiian researchers and more accountable to translating the research into practice and sharing findings with communities. One participant said, "I believe we have to grow our researchers, our surgeons, our physicians so we can trust the work being done." Another said, "Across the board, even with the research, you need more Native Hawaiians involved in the control and understanding [of things]. Granted that most of the research is performed by non-Hawaiians today, I think it is a good opportunity to express that we need more Hawaiians involved in these things, so open up doors."

\section{Option to be Re-consented Each Time One's Specimen is Requested for Research}

Congruent with a call for research transparency, concerns were expressed about loss of control over how biospecimens would be used. For example, one said, "I wouldn't know what the scope of the research would be in the future. They might want to take my tissue to research how to clone something else, I wouldn't want that."

A majority of participants talked about the need to be re-consented each time their tissue was requested for use, as reflected in this response: "If I'm going to give my tissue to anyone for any cause, I want to know what the purpose of that is for. I don't feel comfortable giving a generic sample and willy-nilly let people do what they want with that." Another said, "If you are truly wanting informed consent, true informed consent, even in the legal sense, happens at certain occasions. It's not going to just happen in the beginning and ta-da! you have all the rights. It's going to continue." Another said, "If the study goes against the things I believe in...I want to tell the researchers that I don't want to participate in this study." Some participants noted they would not need to be re-consented if they trusted the researchers and/or the people governing the biorepository.

\section{Education for the Native Hawaiian Community}

Participants raised concerns about the lack of education about biobanking or research that would require tissue to be collected and banked. They wanted to be informed and to have opportunities to discuss research and how Native Hawaiians were and could be involved. As one participant noted, "My own personal view is, if we were better informed, that aloha wouldn't come out so quickly. Our aloha is limitless in my opinion as a Hawaiian community. What I have always seen and believe will continue on, except for the fact that now we are getting more education." In line with this thought, there was mention of the reciprocal nature of research and education. As one participant said, "If they want this from us, we need something from them. Because honestly, enough is enough. We understand that we are helping our people. As a Hawaiian I think we gotta find a way to get our people to help themselves and get them involved in this process and start educating them more." Also, participants in all groups expressed a desire to be kept updated about the activities of the biorepository and of findings from research on banked specimens. Participants felt good options for these communiqués included newsletters, email broadcasts, and web postings. 


\section{Discussion}

Although all focus groups and the vast majority of participants embraced research as a means to improve individual and population health, they also expressed reservations about participating in biobanking because current practices provide the individual little or no control over how their biospecimens are used. They also highlighted strategies to address those concerns, specifically through increased Native Hawaiian participation in governance, education, and research careers, as well as the right to be re-consented each time their banked specimen was requested for study. Participants felt that broader participation from the Native Hawaiian community would help assure that biospecimen-related research was relevant, sensitive, and respectful to their community.

Considered together, these themes yield four recommendations. First, procedures are needed to ensure effective participation of Native Hawaiian people in the governance of biobanks incorporating Native Hawaiian specimens. Second, more education about biobanking, biospecimen research, and research in general is needed. Third, Native Hawaiians and members of other indigenous peoples and minority groups whose participation in biobanks is sought should be provided more opportunities to participate as researchers, educators, and in research agenda-setting. Fourth, as a matter of respect for indigenous people who remember research abuses, consent forms and protocols must include options to be reconsented each time a specimen is requested for use in research.

The research literature suggests generally broad support for biobank participation [17]. However, as we found, studies on indigenous people about biobanking identify reservations that these groups may have about biospecimen banking and research. These concerns stem from knowledge of past research abuses, most notably the case in which the Havasupai Tribe was told that specimens would be used for diabetes-related research, but later found that specimens were used to investigate research questions related to mental illness and ancestry [3]. Members of the tribe felt that this unauthorized use of specimens, “...not only injured the individuals who gave samples, but also caused a collective harm to the Havasupai Tribe and the cultural and spiritual beliefs of its members" [5, p 396]. Hiratsuka and colleagues, in their focus groups with Alaska Natives, identified five themes similar to ours, including a theme related to the potential benefits accruing from medical research, but also themes related to the negative effects of past research (including stigmatization) and of changes to self-determination and culture that have resulted from colonization [9].

The call for more education on biobanking and biospecimen research is not new, but it cannot be overstated. The focus group discussions reinforced that biobanking is an unfamiliar topic. Certainly, for consent to be informed, participants must understand the purpose of the research, the voluntary nature of participation, that no direct benefit may result from the research, the expected duration of participation, potential risks and benefits, and the extent to which confidentiality will be maintained. Participants also must receive contact information for someone they can call with questions about the research and concern about their rights [18]. Potential participants should understand the general intent of use of banked specimens and possible risk that a group or class of participants may be harmed if findings suggest something stigmatizing about that group. They also should understand their 
options for ownership and financial gain (usually there are none), options for re-consenting for each study, and circumstances under which research data will be disclosed to the participant, family, and physician [19]. Given Native Hawaiians' experience with research abuses, special attention and group education on the potential benefits and risks of biobanking must be developed and provided by those seeking tissue donation. Because the nature of research advances is unknown, it is not possible to inform specimen donors of all future potential uses of their banked tissue. Both of these factors are contributors to the erosion of trust between communities that provide samples and researchers who use them.

Thus, it was not surprising that the findings also reveal a demand by respondents for increased engagement of Native Hawaiians in research, in research agenda setting, and in the governance of biorespositories. One example of efforts to increase Native Hawaiian involvement in research is 'Imi Hale Native Hawaiian Cancer Network, a sponsor of this study and one of several programs in Hawai ' $i$ dedicated to increasing the number of Native Hawaiians entering science, technology, engineering, and math fields. 'Imi Hale is specifically charged with developing scholars and community members who want to help reduce cancer health disparities experienced by Native Hawaiians, and since 2000 more than 100 Native Hawaiian community members, students, post-docs, and junior faculty members have received training and mentoring in research methods and in grant and manuscript writing through this program. These trained and credentialed Native Hawaiian researchers could play valuable roles in biobank oversight and governance.

Our data also support the need to design governance structures to assure that biobanking policies and procedures are appropriately directed. In addition to increasing the participation of Native Hawaiians, governance procedures should ensure that community leaders can participate in both oversight and the design of all aspects of the biobanking process, including informed consent procedures, data access protocols, and methods to inform the community about research results. If the leadership is reflective of the targeted populations, it may increase the likelihood that the research agenda is also reflective of the targeted population's needs, thereby increasing community support for the projects. A number of communities are working with academic and medical institutions in the establishment of appropriate biorepository policies $[4,20]$. The international organization, Indigenous Genomic Alliance, is a growing body of indigenous researchers and professionals who can serve as advisors and reviewers related to genomic research involving indigenous peoples.

\section{Limitations}

The opinions expressed by the 92 participants may not represent the opinions of all Native Hawaiians. We made efforts to ensure representative participation by conducting focus groups on five different islands and conducting five focus groups on $\mathrm{O}$ 'ahu, the state's most populous island. We did not see a difference in themes by island. A related limitation may be the high percentage (78.3\%) of female participants. Because participants were recruited through convenience sampling, we did not attempt to achieve a gender balance. The gender distribution in the focus groups likely reflected the gender distribution of the agencies we contracted with to recruit participants, as well as the greater willingness of women to participate in qualitative research then men. We also recognize that bias could have been 
introduced through our choice of focus group questions, although these were derived in collaboration with experts in biobanking and Native Hawaiian health.

We initially were concerned that volunteers for this study might have particularly strong feelings about research or biobanking prior to attending the focus groups. However, prefocus group knowledge of the topic was relatively low (33.7\% of the sample), suggesting that most participants did not have strong feelings for or against biobanking prior to participation. Finding that knowledge of the topic was relatively low validated our decision to offer education prior to asking questions. However, we realize that the education provided could have influenced participant responses, especially information on controversies in biospecimen research with indigenous people [3-6]. Had these controversies not been discussed, the findings may have been different. Despite discussions of past research wrongdoings, however, respondents were generally supportive of medical research while asking for greater participation in research agenda-setting and development.

\section{Conclusion}

Advances in genomic science and the resulting health improvements will result when trust and mutual understanding occurs between researcher and participant. Findings from our focus groups clearly demonstrated that members of the Native Hawaiian community are committed to health improvements and view research as a mechanism to discover new ways to improve health. After being informed about biobanking, participants outlined guidelines that could help to build trust and increase participation. These guidelines can be remembered most easily by the acronym, "GREAT" (Governance, Re-consent, Education,

Accountability, Transparency) Research. As biobanks consider the best ways to conduct quality processes, they can remember that GREAT Research involves the target populations in the Governance, participants have the option to be Re-consented with each specimen use, Education is on-going and informative, Accountable researchers come from the population of focus, the process is Transparent and open, and the Research reflects the priorities of the people. Findings and recommendations from this study are being shared with biobanking facilities in Hawai ' $i$ as they develop protocols for biobanking participation, governance, and education.

\section{Acknowledgments}

This study was supported by the National Cancer Institute, Parent Grant, 'Imi Hale Native Hawaiian Cancer Network (U54CA153459).

\section{References}

1. Vaught JB, Lockhart N, Thiel KS, Schneider KA. Ethical, legal, and policy issues: dominating the biospecimen discussion. Cancer Epidemiol Biomarkers Prev. 2007; 16:2521-2523. [PubMed: 18086753]

2. Taniguchi NK, Taualii M, Maddock J. A comparative analysis of indigenous research guidelines to inform genomic research in indigenous communities. International Indigenous Policy J. 2012; 3(1) Retrieved from: http://ir.lib.uwo.ca/iipj/vol3/iss1/6.

3. Mello MM, Wolf LE. The Havasupai Indian Tribe Case: lessons for research involving stored biologic samples. NEJM. 2010; 36:204-207. [PubMed: 20538622] 
4. Tano ML. Interrelationships amount native peoples, genetic research, and the landscape: need for future research into ethical, legal, and social issues. J Law Med Ethics. 2006; 24:301-309. [PubMed: 16789951]

5. Tsosie R. Cultural challenges to biotechnology: Native American genetic resources and the concept of cultural harm. J Law Med Ethics. 2007; 25:296-411.

6. Santos LA. Indigenous concerns about genetic research. Progress in Community Health Partnerships. 2008; 4:321-327. [PubMed: 20208312]

7. Singeo L. The patentability of the Native Hawaiian genome. Am J Law Med. 2007; 33:119-139. [PubMed: 17547357]

8. Association of Hawaiian Civic Clubs (AHCC). Resolution urging the AHCC to support education in genetics and the ethical issues surrounding genetic studies that impact on Native Hawaiians. Adopted November 13, 2004 at the 45th Annual Convention of the AHCC; Maui HI. 2004.

9. Hiratsuka V, Brown J, Dillard D. Views of biobanking research among Alaska native people: the role of community context. Prog Community Health Partnersh. 2012; 6(2):131-139. [PubMed: 22820223]

10. Hawai ‘i Department of Business, Economic Development, and Tourism. [Accessed 21 September 2013] Population of Hawai 'i. 2012. http://dbedt.hawaii.gov/economic/databook/db2011/

11. Braun KL, Tsark J, Santos L, Aitaoto N, Chong C. Building Native Hawaiian capacity in cancer research and programming: the Legacy of 'Imi Hale. Cancer. 2006; 107(8 Suppl):2082-2090. [PubMed: 16977599]

12. Fong M, Braun KL, Tsark J. Improving Native Hawaiian health through community-based participatory research. Californian J Health Promot. 2003; 1(1):136-148.

13. Fong M, Braun KL, Chang M. Native Hawaiian preferences for informed consent and disclosure of results from genetic research. J Cancer Educ. 2006; 21(Suppl):S47-S52. 2006. [PubMed: 17020502]

14. Hutchison AJ, Johnston LH, Breckon JD. Using QSR-NVivo to facilitate the development of a grounded theory project: an account of a worked example. Int J Social Res Methodol. 2009; 13:283-302.

15. QSR International Pty Ltd. NVivo qualitative data analysis software (Version 10).

16. Pukui, MK.; Haertig, EW.; Lee, CA.; McDermott, J. Nana I ke kumu (Look to the source). Hui Hanai; Honolulu: 1972.

17. Rachul C, McGuire A, Caufield T. Public perceptions and biobanking: what does the research really say? Studies Ethics Law Technol. 2012; 6:3.

18. Haga SB, Beskow LM. Ethical, legal, and social implications of biobanks for genetics research. Adv Genet. 2008; 60:505-544. [PubMed: 18358331]

19. Dressler LG. Biospecimen “ownership”: counterpoint. Canc Epidemiol Biomarkers Prev. 2007; 16:190-191.

20. Meslin EM. The value of using top-down and bottom-up approaches for building trust and transparency in biobanking. Public Health Genomics. 2010; 13:207-214. [PubMed: 20395689] 


\section{Table 1}

Participant Demographics $(\mathrm{n}=92)$

\begin{tabular}{ll}
\hline & $\mathbf{n}=(\%)$ \\
\hline Female gender & $72(78.3)$ \\
Age group & \\
$18-39$ & $20(21.7)$ \\
$40-49$ & $18(19.6)$ \\
$50-64$ & $41(44.6)$ \\
$65+$ & $11(12.0)$ \\
Education & \\
$<$ high school & $5(5.4)$ \\
High school or GED & $15(16.3)$ \\
Some college & $38(41.3)$ \\
Bachelors degree & $18(19.6)$ \\
Post-baccalaureate studies & $13(14.1)$ \\
Employed for wages & $53(57.6)$ \\
Has health insurance & $85(92.4)$ \\
Had heard of biobanking & $31(33.7)$ \\
\hline
\end{tabular}

J Cancer Educ. Author manuscript; available in PMC 2015 September 01. 